\title{
IT, Situation Awareness, and Non-Technical Skills in Cardiac Arrest Teams
}

Sune Dueholm Müller

Aarhus University

sdm@processinnovation.dk
Matilde Kristensen

Aarhus University

matildekristensen@hotmail.dk
Kasper Glerup Lauridsen

Aarhus University

kglerup@clin.au.dk
Marlice Zwanenburg

Aarhus University

mazwa@au.dk
Bo Løfgren

Aarhus University

bl@.clin.au.dk

\begin{abstract}
Technical skills are important for providing efficient treatment of in-hospital cardiac arrests. Nevertheless, research shows that non-technical skills and situation awareness are central to improving quality of care. This study reveals that IT plays a large role in establishing and maintaining situation awareness in cardiac arrest teams. On the one hand, IT allows team members to establish situation awareness. On the other hand, IT draws attention away from the situation, thus negatively impacting situation awareness. Furthermore, this study reveals that non-technical skills are important as they enable effective use of IT and mitigate the negative impact of IT on situation awareness. The impact of IT represents a significant contribution to situation awareness theory, which is discussed along with implications for practice.
\end{abstract}

\section{Introduction}

In 2018, more than 2000 in-hospital cardiac arrests were reported to the national Danish database for cardiac arrest monitoring [1]. The patient survival rate totaled a mere $55 \%$, leading to a call for quality improvement in cardiac arrest treatment [1]. Among the continuous efforts to improve the quality of cardiac arrest treatment, the European Resuscitation Council regularly updates its Guidelines for Resuscitation and provides an Advanced Life Support (ALS) algorithm with technical instructions for effective cardiopulmonary resuscitation (CPR) [2]. Such quality improvement measures are reflected in the research concerned with improving the quality and effectiveness of CPR. The locus of investigations centers on technical skills training and education as well as standardization of processes, equipment, and roles [3, 4].

Furthermore, some hospitals establish dedicated cardiac arrest teams in order to maintain a high level of care. These are most often cross-disciplinary, crossfunctional teams whose compositions vary in terms of size, experience, and medical specialty [5]. Even though these teams are trained to handle critical situations, the stressful situation they face puts teamwork to the test [6]. Therefore, academic interest is also drawn to the importance of non-technical skills in cardiac arrest teams. This category of skills covers interpersonal skills and processes such as leadership, coordination, and communication [7]. Such skills prove important with respect to improving team performance, patient safety, and ultimately the outcome of in-hospital cardiac arrests [8-11]. Furthermore, recent research shows that situation awareness is vital for cardiac arrest team performance [12]. Situation awareness refers to having an overview of one's environment and what is likely to happen in that environment in the future, thus being aware of the situation one is in [13]. Through coordination and communication, team members establish and maintain situation awareness on both an individual and team basis [14].

Medical emergency teams must also interact with several information technologies to provide a high level of patient care $[12,15]$. These include vital sign monitors, electronic medical records (EMR), defibrillators, and smartphones. Such technologies are crucial for cardiac arrest teams as they assess the patient and coordinate critical patient care with other team members [16]. However, it is not clear how IT affects medical emergency teams. Therefore, this paper addresses the following research question: to what extent do information technologies affect situation awareness and non-technical skills in cardiac arrest teams?

This research question guides the inquiry into how existing information technologies affect medical emergency teams. Thus, this research contributes to academic literature as well as practice by shedding light on an under-emphasized but important factor that these medical teams must manage in a critical situation, namely IT. Moreover, it explores how IT affects situation awareness and non-technical skills. With this objective of understanding how IT impacts situation awareness during medical treatment, it is essential to look at the team's communication patterns. Through communication content analysis, the role and impact of IT on communication in cardiac arrest teams is 
evaluated. This approach involves dividing communicative instances into meaningful sequences based on the content expressed [17]. This research design was chosen as it allows for a qualitative analysis of the patterns, interactions, and themes that emerge from the data [18].

This paper is structured as follows. Firstly, background literature on situation awareness and non-technical skills is presented, as well as the current research on the role of IT within these areas. Secondly, the paper's research design and data analysis approach are outlined, followed by the results of the analysis. Lastly, the paper concludes by discussing the theoretical contributions, implications for practice, and directions for future research.

\section{Background literature}

First, this section initially presents background literature on situation awareness and the impact of IT. Second, non-technical skills and their role in medical emergency teams are presented, along with extant knowledge on how IT mediates these skills in medical emergency teams.

\subsection{Situation awareness}

Initially, situation awareness was used as a theory for describing and evaluating fighter pilots' knowledge and understanding of their environment [19]. Situation awareness has in particular been used to investigate how individuals perceive and act in complex, dynamic, and collaborative work environments [20]. Subsequently, the theory gained recognition as a framework for investigating healthcare teams. These teams must make correct and requisite decisions in a stressful environment whilst ensuring optimal patient safety and care [6]. Thus, situation awareness is useful for describing and understanding how healthcare team members make decisions and comprehend the surrounding, high-pressure environment [14].

Endsley [18: 97] gave the most widely agreed upon definition of situation awareness as "the perception of the elements in the environment within a volume of time and space, the comprehension of their meaning, and the projection of their status in the near future." A conceptual model later separated the concept into three levels [13]. Firstly, an actor perceives elements in the environment, such as objects or data. These perceived elements form the basis for comprehension, the second layer of situation awareness. Here, the actor combines and synchronizes perceived data to understand the collective meaning which, in turn, enables the highest level of situation awareness. The actor reaches this level when projecting how the aforementioned elements in the environment will behave in the future. Wright et al.
(2004) exemplify the distinction between the second and third level in terms of healthcare providers being reactive and proactive: whereas level 2 situation awareness allows a physician to reactively understand or identify a diagnosis based on the patients symptoms, level 3 situation awareness is reflected in the physician's ability to proactively project how the patient will react to, e.g., medications or surgical procedures [14].

The oft-cited three-level model has situation awareness as the basis for decision-making and consequent actions. The actor goes through continuous, cognitive feedback loops guided by internal and external factors such as cognitive abilities, goals, expectations, workload, and interface design $[14,20]$. However, the practical implication of situation awareness as a cognitionbased process has been criticized by researchers who allege that actors may not have time to process data perceived in the environment before action is required. Thus, rather than a cognitive process, situation awareness is a continuous cognition-action process, meaning that actions at times guide perception in dynamic situations [21]. This goes to say that actors may not always have time to reflect on the information they are given before acting, and vice versa. Thus, team members adapt to an unfolding, dynamic situation through action and perception rather than through perception, interpretation, and subsequently action.

The three levels are not necessarily linear stages that must be followed sequentially in order to establish situation awareness. Rather, the levels should be thought of as ascending stages of situation awareness, where each level may underlie action [22]. Endsley offers this explanation of the three-level model to indicate that an actor who reaches level 1 situation awareness must not necessarily reach level 3 before making a decision and acting upon it. Instead, such actions may be driven by both goal-oriented and data-driven decisions. Nevertheless, the distinguishing feature of the actor's situation awareness is whether or not they can project the future state of elements in the environment [20,22].

Whereas little research has previously investigated the role of IT in situation awareness, this notion has been discussed on a theoretical level. Advocates of a sociotechnical perspective argue that situation awareness resides not only with the people in the environment, but also in technological devices [23]. Thereby, situation awareness arises from the system as a whole rather than through interaction between human and non-human actors [20]. Endsley (2015) argues, however, that data may very well be distributed across the sociotechnical system and contribute to human actors' situation awareness. Nonetheless, an information technology that displays data does not itself possess situation awareness [22]. 
Thus, a report or information technology in the environment does not possess situation awareness because it displays data. Nevertheless, research shows that existing IT in the actor's environment impacts situation awareness. On the one hand, the way information is structured, distributed, and presented via such information technologies impacts the establishment of situation awareness [24]. Factors, such as information aggregation as well as centralization of the team's information storage and dissemination, affect the team's situation awareness. Thus, if information is summarized and coordinated by a central team member, situation awareness increases. If IT presents team members with non-summarized information, this increases their situation awareness as well. On the other hand, IT can augment or decrease situation awareness. By directing an actor's attention toward fast-changing elements in the environment, IT helps establish situation awareness. By contrast, IT which draws attention away from such elements negatively impacts the establishment of situation awareness [25].

\subsection{Non-technical skills}

Besides situation awareness, focus on teamwork in medical emergency teams has turned toward non-technical skills (at times denominated 'human factors') as deserving of further investigation with regard to their role in cardiac arrest treatment [26]. Communication, teamwork, leadership behavior, planning, role distribution and clarifications, as well as education and training are all non-technical skills essential to providing efficient CPR [7]. However, these skills are not only important to providing optimal CPR in their own right. Castelao et al. (2013) suggest a framework where communication, planning, and leadership are vital non-technical skills that enable another overarching, but nonetheless critical, non-technical skill, namely coordination. Thereby, not only coordination but also the three abovementioned skills are important to cardiac arrest teams. Integrating these non-technical skills should result in better coordination, teamwork, and thus improved patient care [7, 27].

These non-technical skills manifest through clear team structure, role assignment, and information sharing, thus enabling team members to coordinate next steps, understand what others in the team are doing, and identify and disseminate pertinent information to other team members [16]. Besides mastering the technical skills of resuscitation, clinicians must also acquire these non-technical skills. Training and education focusing on non-technical skills is a vital step toward improving quality of care in cardiac arrests [11,28]. Furthermore, education and training are beneficial to clinicians all throughout their careers. Robinson et al. (2016) found vast discrepancies among junior doctors, nurses, and specialized clinicians regarding the presence of strong leadership in cardiac arrest teams [29]. Such variation in leadership abilities suggests a focus on non-technical skills training to improve teamwork in cardiac arrest teams and, ultimately, the quality of care provided by these teams.

Little research has investigated how IT impacts nontechnical skills in cardiac arrest teams. Nevertheless, new developments within IT show the potential for healthcare teams to provide better patient care. IT facilitates cross-functional collaboration of healthcare teams, as opposed to existing IT which is built around silos of specializations. This, in turn, enables non-technical skills in healthcare teams, and consequently, allows these teams to provide better patient care. Thus, IT enables these teams to provide better patient care [30]. Moreover, existing IT solutions show promise in supporting non-technical skills in medical emergency teams [31]. In an emergency surgical team, the instant messaging service WhatsApp was not only viewed by team members as an effective communication medium, it also facilitated time-efficient dissemination and retrieval of information within the team. Thus, existing IT solutions may not only be important for insuring patient safety, their use may also very well support non-technical skills in medical emergency teams.

\section{Research design}

This paper investigates the role of IT already available to cardiac arrest team members. To explore how IT affects team members' situation awareness, a qualitative research design is employed. The qualitative approach allows the researcher to conduct an in-depth investigation in a specific context [18]. Thus, the qualitative research design allows for an in-depth look at how cardiac arrest teams manage existing IT. Given the minimal prior research into this topic, a qualitative investigation provides unique, in-depth insights into the processes and use of IT that affect team members' situation awareness [18].

Specifically, video-recordings of resuscitation training simulations were used and analyzed through communication content analysis. This method allows the researcher to investigate conversations and contextual factors (in this case, IT) and thus analyze how participants make sense of their environment [16]. As this paper seeks to explore how IT affects situation awareness, this methodological base allows for exploration of topics, themes, and uses that arise around IT in these teams $[18,32]$.

Observation data allows an investigation into the interactions among team members as well as with IT that reflect situation awareness [33]. Although observation 
limits the researcher's ability to ascertain whether information is processed by participants [14], it allows the researcher to investigate the behaviors and interactions surrounding the object of interest [18].

Table 1. Scenarios in the data pool. Scenario descriptions and no. of each scenario included in the data pool.

\section{Scenario No. included Scenario description}

in data pool

\begin{tabular}{lrl}
\hline Sepsis (blood infection) & 12 & Elderly man develops blood infection due to a urinary tract infection. \\
\hline $\begin{array}{l}\text { Anaphylaxis (a state of al- } \\
\text { lergic shock) }\end{array}$ & 8 & $\begin{array}{l}\text { Elderly woman with pneumonia goes into anaphylactic shock after } \\
\text { penicillin is administered. }\end{array}$ \\
\hline $\begin{array}{l}\text { Ventricular tachycardia } \\
\text { (abnormal heart rhythm) }\end{array}$ & 12 & $\begin{array}{l}\text { Elderly man with pneumonia goes into cardiac arrest after develop- } \\
\text { ing a thrombosis. }\end{array}$ \\
\hline Asystoli (no heart rhythm) & 8 & Elderly woman admitted with hip fracture found lifeless in bed. \\
\hline $\begin{array}{l}\text { Ventricular fibrillation (ab- } \\
\text { normal heart rhythm) }\end{array}$ & 8 & Elderly woman recently operated following a heart attack. \\
\hline Pulseless electrical activity & 8 & Young man found lifeless in bed after recent abdominal surgery. \\
\hline Total & 56 & \\
\hline
\end{tabular}

\subsection{Data collection}

In order to analyze how IT affects situation awareness in cardiac arrest teams, audio-visual footage was captured at an ALS course for newly employed residents at public teaching hospitals in two regions of Jutland, Denmark. The course makes up part of the basic training for postgraduates and lasted one day. The course was made up of intermittent theoretical lectures and simulation training. Each course had between 18 and 21 participants divided into four teams of between three and five people.

The training course took place in specially designed simulation labs that were designed to mimic a standard hospital room. The course includes 12 unique simulations carried out using the Resusci Anne ${ }^{\circledR}$ patient simulator [34]. In total, 56 scenarios were included in the final data pool (see Table 1). The scenarios centered around six different simulations (see Table 1) and focus on practicing the procedures and guidelines for treating cardiac arrest.

In order to minimize interference with the teaching situation, observer participation was limited to informal interactions with participants before and after the simulations, mostly to inform about the objective of the research and answer any questions that arose. Therefore, cameras were set up and started recording before participants entered the rooms; this way, minimal interference was ensured. However, the observer was present and stayed in close proximity to the simulation rooms in case of technical difficulties.

Participants and course instructors were informed of their right to decline being recorded as well as their right to withdraw their consent at any given time. Additionally, participants were informed of the handling of their personal data according to EU's GDPR regulation, and that all person-sensitive data would be anonymized.
Furthermore, participants were advised that direct quotes would not be used in the final article, and all sensitive data would be deleted upon project completion. All participants agreed to be recorded. The study has been approved by the regional committee on health research ethics and complies with all applicable data protection laws.

\subsection{Communication content analysis}

To analyze the communication patterns in medical emergency teams, a communication content analysis framework similar to that of Parush and colleagues [12, 16] was adopted. This approach meant segmenting the full communication protocols of the medical emergency teams into meaningful sequences consisting of at least two participants exchanging information relevant to the situation [16]. In addition, instances where IT was used, or where participants managed information through IT use, were coded. This process of identifying and coding communication sequences was used with the objective of identifying the processes and communication patterns that reflect building and maintaining situation awareness through IT use.

In order to determine the situation awareness possessed by the team, communication sequences were analyzed according to the three-level situation awareness model: perceiving elements in the environment (level 1), comprehending the current situation (level 2), and projecting how elements in the environment will behave in the future (level 3) [13]. Using the qualitative analysis software NVivo, several communication content codes were assigned to the data: situation-specific content of the communication was noted as a marker for whether team members showed awareness of the elements in their environment (level 1). These were aggregated during data analysis and included patient history, team 
members present, and time. Team members' comprehension of the unfolding situation (level 2) was noted on the basis of being able to recognize and react to problems in their environment, e.g., through interventions or therapeutics. Lastly, indicators of level 3 situation awareness included content related to projections of how elements in the environment would behave in the future. Such codes included content on, e.g., required future treatment and consultations (see Table 2 for additional insight and examples from the coding scheme; please consult the analysis protocol here: https://u.pcloud.link/pub$\underline{\text { link/show? code }=\text { XZbSVIkZN7SGu02X19RsKFzXB1 }}$ xck41RfSI7).

Table 2. Coding scheme excerpt. Theoretical constructs, derivative codes, and example utterances.

\begin{tabular}{|c|c|c|c|}
\hline Construct & Description & Codes & Examples \\
\hline \multirow{5}{*}{$\begin{array}{l}\text { Level } 1 \\
\text { situation } \\
\text { aware- } \\
\text { ness }\end{array}$} & \multirow{5}{*}{$\begin{array}{l}\text { Perceptions of } \\
\text { elements in the } \\
\text { environment }\end{array}$} & Patient status & "Patient found unresponsive, no pulse." \\
\hline & & Patient history & Team leader: "Who is the patient?" \\
\hline & & & $\begin{array}{l}\text { Nurse: "This is Daniel, had an appendectomy this } \\
\text { morning, smooth procedure, last seen up and about } \\
\text { this morning." }\end{array}$ \\
\hline & & Time & $\begin{array}{l}\text { Team leader: "How are we doing on time?" } \\
\text { Anesthesiology: "1 min. } 40 \text { [sec.]." }\end{array}$ \\
\hline & & Team members present & "Anesthesiology present" \\
\hline \multirow{4}{*}{$\begin{array}{l}\text { Level } 2 \\
\text { situation } \\
\text { aware- } \\
\text { ness }\end{array}$} & \multirow[t]{4}{*}{$\begin{array}{l}\text { Comprehension of } \\
\text { the current } \\
\text { environment }\end{array}$} & $\begin{array}{l}\text { Interventions (such as in- } \\
\text { vestigations and drug ad- } \\
\text { ministrations) }\end{array}$ & $\begin{array}{l}\text { Team leader: "Administer } 1 \mathrm{mg} \text { adrenaline." } \\
\text { Nurse: "1mg adrenaline ready. Administering now." }\end{array}$ \\
\hline & & $\begin{array}{l}\text { Calling code (announcing } \\
\text { a cardiac arrest and sum- } \\
\text { moning the cardiac arrest } \\
\text { team) }\end{array}$ & $\begin{array}{l}\text { "No pulse. Patient is in cardiac arrest. Call the car- } \\
\text { diac arrest team." }\end{array}$ \\
\hline & & Role clarifications & $\begin{array}{l}\text { Team leader: "You're anesthesiology, right?" } \\
\text { "Yes." }\end{array}$ \\
\hline & & Task status & "I have free hands." \\
\hline \multirow[t]{3}{*}{$\begin{array}{l}\text { Level } 3 \\
\text { situation } \\
\text { aware- } \\
\text { ness }\end{array}$} & \multirow[t]{3}{*}{$\begin{array}{l}\text { Projection of } \\
\text { future status }\end{array}$} & $\begin{array}{l}\text { Assistance and consulta- } \\
\text { tions }\end{array}$ & $\begin{array}{l}\text { [Calling cardiology department] "Hi, I need someone } \\
\text { to come down and perform an ultrasound. 26-year } \\
\text { old male, found unresponsive, suspected pulmonary } \\
\text { embolism." }\end{array}$ \\
\hline & & $\begin{array}{l}\text { Reversible causes, future } \\
\text { treatment, and interven- } \\
\text { tions) }\end{array}$ & $\begin{array}{l}\text { "So, if we go through the } 4 \mathrm{Hs} \text { and the } 4 \mathrm{Ts} \text {, I sus- } \\
\text { pect hypovolemia, the patient is bleeding from his } \\
\text { surgery. We need to contact the surgeon on call, } \\
\text { and can you put up } 11 \text { saline solution?" }\end{array}$ \\
\hline & & Task assignment & "Next round, please switch with the orderly on CPR." \\
\hline \multirow[t]{4}{*}{ IT } & Vital sign monitors & $\begin{array}{l}\text { Blood pressure and satu- } \\
\text { ration monitors }\end{array}$ & $\begin{array}{l}\text { "Okay, you measure blood pressure, l'll find a satu- } \\
\text { ration monitor." }\end{array}$ \\
\hline & Defibrillator & Defibrillator & $\begin{array}{l}\text { Anesthesiologist: "Rhythm check, stop CPR. This } \\
\text { looks like sinus rhythm, is there a pulse?" } \\
\text { Nurse: "Yes, there's pulse." }\end{array}$ \\
\hline & Smartphones & Phone & $\begin{array}{l}\text { "Nurse, please call the cardiologist on call for a con- } \\
\text { sultation." }\end{array}$ \\
\hline & EMR & EMR & $\begin{array}{l}\text { Team leader: "Does anyone know his pharmacologi- } \\
\text { cal history?" } \\
\text { Nurse: "I'll look it up." }\end{array}$ \\
\hline
\end{tabular}

\section{Results}

This section presents the results of the analysis structured according to the three levels of situation awareness. Each section further emphasizes how IT affects situation awareness as well as non-technical skills.

\subsection{Level 1 situation awareness}

Monitors displaying vital signs were used in all scenarios before the resuscitation and in a majority of cases after the resuscitation. As the simulated hospital room setting had a limited selection of these monitors, only blood pressure and blood saturation apparatuses were available. Nonetheless, participants used vital sign 
monitors to track the patient's vital signs, thereby gaining insight into the patient's status. Thus, vital sign monitors facilitated an assessment of a critical patient by providing data about elements in the environment.

Some participants attempted to measure blood pressure and saturation levels during CPR; however, as the patient had no spontaneous circulation of blood, other team members (or the teacher) informed them that these cannot be measured when the patient is dead. This shows that team members attempted to establish situation awareness, as they sought to collect more data about the patient, through IT use.

Whereas vital sign monitors were used before and after the cardiac arrest, electronic medical records (EMR) were the most used information technology for gathering data regarding the patient during the resuscitation attempt. All teams used these records to some extent for looking up the patient's laboratory results (e.g., blood or urine test results) as well as previous medical, surgical, and pharmacological histories. Thus, EMR helped the actors establish situation awareness during the heart attack. Furthermore, participants used EMR to facilitate situation awareness during treatment and monitoring of the critically ill patients before the onset of cardiac arrest. This, in turn, meant that participants were able to read about drug administrations and gain insight into the patient's medical history and prior symptoms such as continuous abdominal pain or difficulty breathing. Consequently, EMR helped participants understand and diagnose the patient, as well as ultimately treating the patient. Thus, through providing data about the patient, EMR helped the team members establish level 1 situation awareness.

\subsection{Level 2 situation awareness}

Besides establishing level 1 situation awareness, EMR also facilitated the establishment of level 2 situation awareness. This higher level of situation awareness requires that cardiac arrest team members synchronize information collected at level 1 to establish a more holistic comprehension of the situation. This synchronization was seen when participants drew on data obtained at level 1 regarding pharmacological history, vital signs, etc. to diagnose the patient. This occurred, for example, in the anaphylaxis case (see Table 1) where all teams concluded that the patient's rash, vital signs, throat closure, and recent penicillin administration indicated that the cardiac arrest was due to anaphylactic shock. Participants therefore used IT to gather data in the environment, facilitating a more holistic view of the situation and enabling them to put forth a diagnosis.

In this synchronization process, EMR was furthermore employed to gain additional insight into the patient's treatment history. For example, knowing a patient had recently undergone heart surgery made it obvious for participants to contact a cardiologist to ascertain whether a thrombosis was the cause of the patient's cardiac arrest.

Smartphones played a large role in facilitating higher levels of situation awareness. These were used for, e.g., keeping time upon diagnosing the cardiac arrest and calling the cardiac arrest team. This demonstrates a high level of situation awareness, as participants knew that taking time is quintessential for, e.g., drug administration and rhythm analyses. Thus, participants perceived and interpreted information about the environment and concluded that taking time was necessary for the treatment. Furthermore, the smartphone's timer feature helped the participant facilitate level 2 situation awareness.

\subsection{Level 3 situation awareness}

To establish the highest level of situation awareness, participants used diagnostic tools such as echocardiogram (ECG) and ultrasound machines. Two team leaders contacted a cardiologist with the express purpose of performing an ultrasound of the heart to confirm whether the patient suffered from a thrombosis. These requests for further diagnostics indicate that participants sought further information regarding the patient's status or diagnosis. By way of example, a team leader requested an emergency scan upon discovering the patient might suffer internal bleeding. Thus, participants used diagnostic tools to establish a diagnosis. By putting forth a diagnosis, participants were able to start treatment, illustrating level 3 situation awareness.

Besides using their smartphones for time management, team members also used them to contact experienced physicians for consultations regarding the patient's status. These senior physicians were called to the room to consult with team members and draw on their expertise. In a few cases, participants suspected the patient was hemorrhaging from a recent surgery. Thus, they contacted a senior cardiologist or surgeon on call to consult with them on how to approach diagnosing and treating the patient. This shows a high level of situation awareness since team members concluded that certain expertise was needed to prevent the patient's condition from deteriorating even further (i.e., emergency surgery to locate and stop the patient's internal bleeding). The team members therefore demonstrated level 3 situation awareness by projecting what was required in the future.

\subsection{Non-technical skills and IT use}

Besides enabling the team members to gain higher levels of situation awareness, smartphones also enabled the non-technical skills of coordination and 
communication. By consulting specialized physicians, participants communicated with them regarding the cardiac arrest situation. However, contacting these experienced physicians also allowed participants to coordinate future care and treatment. One example of this is a team member who contacted the cardiothoracic surgeon on call to coordinate emergency surgery for a thrombosis. Thus, the team coordinated the immediate surgery and communicated with the surgeon regarding the patient's status.

By contrast, participants noted that in particular managing the defibrillator impeded their ability to establish and maintain situation awareness. This was because the defibrillator occupied and drew away focus from the unfolding situation. However, participants also noted that leadership behavior mitigated this negative impact. By delegating responsibility for managing the defibrillator to one team member, it meant the remaining team members were able to concentrate on maintaining an overview of the situation and caring for the patient.

Conversely, the defibrillator also affected the team leaders' ability to manifest non-technical skills such as leadership. Such leadership was defined as keeping an overview of the situation, delegating tasks, and ensuring clear, closed-loop communication with other team members. Participants noted that while in the role of team leader, IT negatively impacted their ability to maintain situation awareness and demonstrate leadership. Particularly managing the defibrillator and looking up patient details in the EMR impeded their ability to simultaneously exert leadership and maintain situation awareness. Thus, IT and non-technical skills affected one another, as task delegation and coordinating responsibility supported team members in managing cognitively demanding IT. Vice versa, managing these information technologies negatively affected the team members' ability to exert leadership and coordination behaviors.

In summary, IT had a significant impact on situation awareness in cardiac arrest teams. Where vital sign monitors and EMR supported their establishing level 1 and level 2 situation awareness, smartphones and diagnostic tools played an important role in their establishing level 3 situation awareness. Furthermore, smartphones were instrumental in enabling the nontechnical skills of communication and coordination. However, the analysis also revealed that particularly the defibrillator impeded the establishment of situation awareness, which in turn affected the team members' ability to exert leadership and coordination behaviors.

\section{Discussion}

This study sheds light on a hitherto under-emphasized area of research on medical emergency teams by investigating the role of IT in establishing situation awareness. Nonetheless, this study confirms the results of prior research by highlighting that IT can hinder situation awareness [25]. By drawing actors' attention away from the unfolding situation, IT impedes their ability to establish situation awareness. However, the results of this study suggest that the actors' particular environment and goals have a mediating effect on the way IT supports or hinders situation awareness. In contrast with a previous study, this paper finds that smartphones have a positive impact on participants' situation awareness [25]. This is due to smartphones supporting the highly goal-oriented task of coordinating patient care with experienced colleagues. Thus, the goal of resuscitating the patient may influence actors' use of IT.

This, in turn, has implications for the design of such IT. Although the present study does not take into account design features, prior research suggests that presentation and structure of data can affect actors' situation awareness [24]. Thus, while IT, such as the defibrillator, negatively impacts situation awareness, this may be mitigated by organizational and design factors. By ensuring information centralization and dissemination within the team by, e.g., putting one team member in charge of managing the defibrillator and providing team members with summary information, team members' situation awareness should increase. Such summary information could be provided through automation of the heart rhythm analysis, thereby presenting team members with information about the heart's electrical system and what that information indicates.

This study also adds to the theoretical discussion of situation awareness on two fronts: first, the results show that IT impacts different levels of situation awareness, which in turn leads to actions and decisions to, e.g., contact colleagues, administer treatment, and continue diagnosing the patient. This supports Endsley's argument that the layers of situation awareness are not successive and linear [22]. Second, the present paper contributes by showing that attaining the different levels of situation awareness is facilitated by IT. Whereas smartphones were important for participants in the cardiac arrest scenarios to maintain level 2 and level 3 situation awareness, other types of IT helped establish level 1 and level 2 situation awareness. Such types of IT included vital sign monitors and EMR, and data from these technologies helped the team members collect and synchronize information about their environment. This suggests that particular types of IT may enable team members' situation awareness at different levels. On a speculative note, the present study suggests that knowledge management 
systems and diagnostic tools support level 1 and 2 situation awareness. In turn, level 3 situation awareness is supported by types of IT that enable further insight into elements of the environment. They include communication tools such as smartphones. Nevertheless, further research is needed to determine how various design features and functionalities of IT affect the distinct levels of situation awareness.

Besides impacting cardiac arrest team members' situation awareness, IT also enables non-technical skills. One such technology is the smartphone; by enabling the non-technical skills communication and coordination, team members establish higher levels of situation awareness. This adds to the finding by Johnston et al. (2015) that existing IT has the potential to improve safety, coordination, and communication between members of medical emergency teams [31]. Through existing technology, team members can communicate with experienced colleagues, thus drawing on their expertise and experience when diagnosing the patient. IT therefore helps cardiac arrest teams save time in confirming a diagnosis and subsequently starting life-saving treatment in a situation where time is of the essence. This, in turn confirms that IT shows promising potential in supporting cross-functional team structures and allowing team members to communicate more efficiently, and in a hospital setting providing better patient care [30]. On a speculative note, existing IT, such as smartphones, shows promise in terms of increasing patient safety through quick diagnosis and treatment of reversible causes in case of cardiac arrest. However, future research is needed to determine the impact of IT on patient safety during cardiac arrest treatment.

Furthermore, this study reveals that IT necessitates non-technical skills as well. Particularly coordination and leadership are important non-technical skill which help team members maintain situation awareness. This confirms the importance of non-technical skills in providing better quality of care [7]. Moreover, this study shows that non-technical skills are important in managing IT during cardiac arrest treatment. Whereas leadership and coordination help mitigate the negative effects of IT on team members' situation awareness, these nontechnical skills are also impacted by cognitively demanding IT. Thus, IT also affects team leaders' ability to leverage these non-technical skills if they simultaneously have to manage IT that impacts their situation awareness. This study thus adds to extant literature by highlighting the reciprocal relationship between cognitively demanding IT and the non-technical skills leadership and coordination behavior.

This has implications for practitioners, as clinicians (particularly team leaders) who are aware of this reciprocity between IT, non-technical skills, and situation awareness can use this knowledge to their advantage. By being aware of and consciously using non-technical skills, team leaders can actively contribute to performance improvements of medical emergency teams. In turn, this improves the quality of CPR performed by the team.

\subsection{Limitations and future research directions}

One shortcoming of the present study is that it focuses on learning scenarios and simulation studies. Although high-fidelity training scenarios are important for improving and training both technical and non-technical skills in cardiac arrest teams, there are many differences to in situ simulations or actual in-hospital cardiac arrests [35]. Therefore, further research is needed to investigate the role of IT in more realistic settings.

Nonetheless, this study has broken into an area that merits future research. Although this research has shown a link between situation awareness, non-technical skills, and IT, the relationship between and mediating effects of the aforementioned factors have not yet been mapped. Extant literature describes several studies of cognitive aids that support situation awareness [12, $15,16]$. However, this study highlights the potential that lies in existing IT, both in terms of supporting and negatively impacting situation awareness. Thus, future research should investigate the factors that mediate and affect this relationship. Furthermore, future research should determine whether the negative impact of IT on situation awareness is the same for non-technical skills, as the results of this study suggest.

\section{Conclusion}

This study reveals that information technologies significantly affect situation awareness and non-technical skills. Through observation of simulated cardiac arrests, this study investigates the use of existing IT in cardiac arrest teams. These include vital sign monitors, EMR, smartphones, and defibrillators. Whereas EMR and vital sign monitors are important for establishing level 1 and level 2 situation awareness, smartphones help establish level 2 and level 3 situation awareness. Moreover, the study shows that IT enables non-technical skills which, in turn, mitigate the negative impact of IT on situation awareness.

The impact of IT on situation awareness and nontechnical skills is important to take into account, as it affects team members and cardiac arrest treatment. However, by drawing attention to this fact, clinicians can use this knowledge to their advantage, thereby improving cardiac arrest team performance. This study thus takes an important step toward improving the quality of in-hospital cardiac arrest treatment. 


\section{References}

[1] DANARREST, "National årsrapport 2018”, May 2019.

[2] Monsieurs, K.G., et al., "European Resuscitation Council guidelines for resuscitation 2015: Section 1. Executive summary”, Resuscitation, 2015. 95: pp. 1-80.

[3] Devita, A., et al., "Improving medical crisis team performance", Critical Care Medicine, 2004. 32(2): pp. 61-65.

[4] Larsen, T., et al., "Conducting the emergency team: A novel way to train the team-leader for emergencies", Heliyon, 2018. 4(9): pp. 1-27.

[5] Lauridsen, K.G., et al., "Organisation of in-hospital cardiac arrest teams - a nationwide study", Resuscitation, 2015. 89: pp. 123-8.

[6] Hunziker, S., et al., "Dynamics and association of different acute stress markers with performance during a simulated resuscitation", Resuscitation, 2012. 83(5): pp. 572-578.

[7] Castelao, E.F., et al., "Effects of team coordination during cardiopulmonary resuscitation: A systematic review of the literature", Journal of critical care, 2013. 28(4): pp. 504-521.

[8] Hunziker, S., et al., "Human factors in resuscitation: Lessons learned from simulator studies", Journal of emergencies, trauma and shock, 2010. 3(4): pp. 389-394.

[9] Flowerdew, L., et al., "Identifying nontechnical skills associated with safety in the emergency department: A scoping review of the literature", Annals of emergency medicine, 2012. 59(5): pp. 386-394.

[10] Prince, C.R., et al., "Finding the key to a better code: Code team restructure to improve performance and outcomes", Clinical medicine \& research, 2014. 12(1-2): pp. 4757.

[11] Andersen, P.O., et al., "Identifying non-technical skills and barriers for improvement of teamwork in cardiac arrest teams", Resuscitation, 2010. 81(6): pp. 695-702.

[12] Calder, L.A., et al., "Team communication patterns in emergency resuscitation: A mixed methods qualitative analysis", International journal of emergency medicine, 2017. 10(1): pp. 24-32.

[13] Endsley, M.R., "Toward a theory of situation awareness in dynamic systems", Human factors, 1995. 37(1): pp. 32-64.

[14] Wright, M.C., J. Taekman, and M. Endsley, "Objective measures of situation awareness in a simulated medical environment", BMJ Quality \& Safety, 2004. 13(suppl 1): pp. i65i71.
[15] Parush, A., et al., "Can teamwork and situational awareness (SA) in ED resuscitations be improved with a technological cognitive aid? Design and a pilot study of a team situation display", Journal of biomedical informatics, 2017. 76: pp. 154-161.

[16] Parush, A., et al., "Communication and team situation awareness in the OR: Implications for augmentative information display", Journal of biomedical informatics, 2011. 44(3): pp. 477-485.

[17] Parush, A., et al., "Exploring similarities and differences in teamwork across diverse healthcare contexts using communication analysis", Cognition, technology \& work, 2014. 16(1): pp. 47-57.

[18] Patton, M.Q., Qualitative research \& evaluation methods: Integrating theory and practice, 4 th ed, Sage publications, California, 2014.

[19] Endsley, M.R., "Situation awareness global assessment technique (sagat)", in Proceedings of the IEEE 1988 national aerospace and electronics conference, 1988, pp. 789-795.

[20] She, M. and Z. Li, "Team situation awareness: A review of definitions and conceptual models", in International Conference on Engineering Psychology and Cognitive Ergonomics, 2017, pp. 406-415.

[21] Gorman, J.C., N.J. Cooke, and J.L. Winner, "Measuring team situation awareness in decentralized command and control environments", Ergonomics, 2006. 49(12-13): pp. 13121325.

[22] Endsley, M.R., "Situation awareness misconceptions and misunderstandings", Journal of Cognitive Engineering and Decision Making, 2015. 9(1): pp. 4-32.

[23] Stanton, N.A., "Situation awareness: Where have we been, where are we now and where are we going?", Theoretical Issues in Ergonomics Science, 2010. 11(1-2): pp. 1-6.

[24] Van de Walle, B., B. Brugghemans, and T. Comes, "Improving situation awareness in crisis response teams: An experimental analysis of enriched information and centralized coordination", International Journal of Human-Computer Studies, 2016. 95: pp. 66-79.

[25] Ma, R. and D.B. Kaber, "Situation awareness and workload in driving while using adaptive cruise control and a cell phone", International Journal of Industrial Ergonomics, 2005. 35(10): pp. 939-953.

[26] Hunziker, S., et al., "Teamwork and leadership in cardiopulmonary resuscitation", Journal of the American College of Cardiology, 2011. 57(24): pp. 2381-2388. 
[27] Manser, T., "Teamwork and patient safety in dynamic domains of healthcare: A review of the literature", Acta Anaesthesiol Scand, 2009. 53(2): pp. 143-51.

[28] Hagemann, V., et al., "Does teaching non-technical skills to medical students improve those skills and simulated patient outcome?", International journal of medical education, 2017. 8: pp. 101.

[29] Robinson, P.S., E. Shall, and R. Rakhit, "Cardiac arrest leadership: In need of resuscitation?", Postgraduate medical journal, 2016. 92: pp. 715-720.

[30] Walker, J.M. and P. Carayon, "From tasks to processes: The case for changing health information technology to improve health care", Health Affairs, 2009. 28(2): pp. 467-477.

[31] Johnston, M.J., et al., "Smartphones let surgeons know WhatsApp: An analysis of communication in emergency surgical teams", The American Journal of Surgery, 2015.

209(1): pp. 45-51.

[32] Parush, A., et al., "A communication analysis methodology for developing a cardiac operating room team-oriented display", in Proceedings of the Human Factors and Ergonomics Society Annual Meeting, 2009, pp. 728-731.

[33] Bearman, C., et al., "A literature review of methods for providing enhanced operational oversight of teams in emergency management", International Journal of Emergency Management, 2018. 14(3): pp. 254-274.

[34] Laerdal Medical, "Resusci Anne ${ }^{\circledR}$ simulator", 2020 [cited 2020, May 6], available from:

https://www.laerdal.com/us/products/simulation-training/emergency-care-trauma/resusci-anne-simulator/.

[35] Krogh, K.B., et al., "Time matters-realism in resuscitation training", Resuscitation, 2014. 85(8): pp. 1093-1098. 